By WYLLIS E. WRIGHT

\title{
The Recataloging Program of the Army Medical Library
}

W

HEN Dr. Billings created the IndexCatalogue of the Library of the Surgeon-General's Office he brought into being a magnificent bibliography which for inclusiveness and ease of use is without parallel in any other subject field. The combination of a typical library catalog in book form with a detailed subject analysis of periodicals proved such an efficient tool that it inhibited the normal development of a card catalog of the library. The result has been, as stated in the survey of the Army Medical Library, that, with the passing of years and the steady growth in the number of volumes of the Index-Catalogue, "its value as a bibliography has increased, while its value as a library catalog has steadily decreased."

The Index-Catalogue was unsatisfactory as a library catalog for two principal reasons. It did not give any indication of the shelf-location of the books listed and its multiplying alphabets made consultation to see whether a work was in the library a tedious affair. The first of these difficulties was undoubtedly a result of the library's complete lack of any classification in the usual sense. When it became necessary to indicate in some way the location of volumes in the growing library, Dr. Billings instituted a system of writing out the complete name of the subject, without symbols or abbreviations. The classes so created have been occasionally combined or further subdivided without alteration of the class name

1 Paper presented at the meeting of the Division Association, San Francisco, July I, I947. as written on the book plate and inconsistencies in the use of such forms as "Malaria," "Malarial fever," and "Fever, Malarial" or "Medical anecdotes" and "Anecdotes, Medical" have frequently occurred. Since even these unsatisfactory substitutes for a classification appeared neither on the backs of the books nor in the IndexCatalogue, difficulties arose in locating and shelving books.

In 1918 and 1919 advantage was taken of the availability of assistance from Army enlisted personnel to clip and mount on cards the author entries from the first two series of the Index-Catalogue. The clipping was done so as to secure as many entries as possible on a single card. Therefore, when the two series were interfiled, alphabetic sequence could not be maintained. Throughout the I920's adequate assistance was not available and no work was done toward including in this file the entries from the third series. With the beginning of the fourth series, a card for each monograph was prepared and filed in the catalog. As time was available, the classification was written on the various cards, but this work has never been completed and the catalog so created has never been satisfactory.

This was the picture when in 1942 the survey committee sponsored by the American Library Association recommended that the existing catalog be totally done away with and a new classification and new catalog prepared in order to make available the splendid resources of this library.

In accordance with these recommenda- 
tions, a committee under the chairmanship of Mary Louise Marshall, librarian, Rudolph Matas Medical Library, Tulane University, New Orleans, began work on a completely new medical classification. This classification has been built up with the advice of experts in various fields of medicine and was finally completed in the spring of 1946. It is a very detailed classification, perhaps even too detailed for the large collection of the Army Medical Library. The committee believed, however, that it is better policy to prepare a classification that would be too minute but could be simplified if desired, rather than one which would be found, after actual trial, to need further expansion. By agreement with the Library of Congress, which was represented on the committee, the classification, after it has been tested in the Army Medical Library, will be printed as a volume in the series of Library of Congress classification schedules and will serve as a revision of the present class "R." In order to prevent confusion and to enable those libraries which are already using the $\mathrm{Li}$ brary of Congress medical classification to continue to use it, if they do not feel able to reclassify, the new classification has been based on the letter "W," previously unused by the Library of Congress.

\section{Photostated Shelflist}

While the classification was being prepared a special staff was recruited to push through the making of a shelflist, which had never existed in the library. This group took each class in turn and made, working from the title page only, a rough shelflist of all the monographs. When this project was completed, early in 1946, the group turned to the binding of the collection of unbound pamphlets. All pamphlets in decent physical condition have now been bound and the volumes, properly shelflisted, added to the permanent collections.
While work was being done on the pamphlets, the shelflist was duplicated by means of photostat and the photostated cards, bearing correct class marks, filed in the card catalog. Since the shelflist cards were made from title pages only, it was recognized that there would be many discrepancies in form and fulness of entries. Since the purpose of these cards was to serve as a checklist of the volumes actually found in the library and not as an exact bibliography, all entries under a surname were filed alphabetically by title and not by forename or initials. While this is not a satisfactory catalog, it does enable the acquisition division to state with some confidence that a book is or is not in the library, and helps the reference division to produce a definite volume when called for.

\section{Catalog Division 'Created}

In the autumn of 1944 plans were laid for the creation of a catalog division to undertake the recataloging of some halfmillion volumes and an equal number of pamphlets and theses. There was general agreement that the cataloging should be simple and we hoped for a rate of descriptive cataloging of one volume every fifteen minutes. To handle a million items in ten years, which was the period set for completion of the recataloging, this called for a dozen descriptive catalogers, with enough additional workers to carry the current acquisitions. With a suitable proportion of subject catalogers and with clerical workers for the many clerical operations of cataloging, a staff of forty-five was planned for the catalog division. Unfortunately this figure has never been reached so that the recataloging has not gone forward with the speed originally expected.

When the creation of a separate catalog division was approved, the work of cataloging was removed from the Index-Catalogue division, which had previously been respon- 
sible for the card catalog as well as for the Index-Catalogue. To head the new division the library was fortunate to secure M. Ruth MacDonald, then chief of the catalog department at the Detroit Public Library. Miss MacDonald, with characteristic energy, tackled a threefold problem -the recruiting of a staff, the preparation of a manual of procedures, and the drawing up of a code of simplified cataloging rules.

With the struggle to secure a staff in the past two years you are all too familiar. It is enough to say that, while the Army Medical Library has secured some of the best cataloging talent in the country, it never has had the size staff it needs. In the other two undertakings success was realized. The catalog division has a set of procedures and a manual to codify them and to instruct new members of the staff, created from nothing in a year's time, that can serve as a model for any library. If the staff were built up to the proportions originally intended, there is no doubt that the load of one hundred thousand recataloged items and sixty thousand new items could be handled smoothly, efficiently, and rapidly.

\section{Simplified Treatment Followed}

The cataloging rules call for a simplified treatment of descriptive cataloging that is still sufficient to identify any item in this great collection of medical literature. Proper names will be established on the basis of a limited number of reference works only, chief reliance being placed on the $\mathrm{Li}$ brary of Congress catalog and the IndexCatalogue. If a name is not found in either of these sources, and there is no conflict with another name, the form in the book will be followed. Titles will be brief and will not include the author's name unless this is needed for sense or grammar.
Pagination is reduced to a statement of the final Roman and Arabic numbers. The simple statement "illus." will serve for all types of illustration except portraits, which will be noted because of the library's interest in medical portraiture. Size will be given at the particular request of the $\mathrm{Li}$ brary of Congress. Notes are used as sparingly as possible. These rules were adopted before the Library of Congress moved actively to simplify its own rules for description and will undoubtedly be modified in detail to conform to the new L. C. rules when these are published.

The subject headings used in the IndexCatalogue have been extensively criticized among medical librarians and bibliographers because of a heavy use of foreign and technical terms when adequate specific English terms are in common use. The Index-Catalogue has also shifted back and forth between synonymous terms in an endeavor to publish its accumulating entries as early as possible. For these reasons it was decided to institute a new list of subject headings for the card catalog. This list is built on the list of subjects used in the catalog of the New York Academy of Medicine which was, in turn, based on the headings of the Quarterly Cumulative Index Medicus and the original series of the Index-Catalogue. Little help was secured from the medical subjects of the Library of Congress, which were wholly inadequate for a special collection.

There has been a large amount of discussion among librarians in recent years regarding the possibility of relying on bibliographies for a subject approach to books and thus of relieving the catalog department of the necessity of creating a list of subject headings and a subject catalog. One great difficulty with such an arrangement has been the lack, in many fields, of adequate bibliographies. In the field of 
medicine the bibliographic approach has been made easy through the existence of the Quarterly Cumulative Index Medicus and the Index-Catalogue. If bibliographies can replace subject catalogs anywhere, the library which, from its own resources, creates one of the standard bibliographies in its field should provide a suitable spot for putting the theory into operation. Thus it was decided not to attempt a complete subject catalog of the library. The author catalog will contain a record of every item in the library. The subject catalog will list, in a separate alphabet, the monographs of the past twenty-five years, plus entries for histories, bibliographies, and other standard reference works which do not become out-of-date. 'The period of twentyfive years was agreed on since it is expected that, in the new building for the library, these monographs will be kept in an open stack accessible to readers, and because the Index-Catalogue requires approximately that amount of time to complete its progress through the alphabet. It is probable that in the future the Index-Catalogue will be published more rapidly, and the period during which the subject cards will remain in the subject catalog will be correspondingly reduced.

\section{A National Medical Library}

The Army Medical Library, although a division of the Office of the Surgeon-General of the Army, is in fact a national medical library and makes its services available not only to other departments of the government but to physicians and students throughout the country. One of the services which American libraries have come to expect from their national libraries is the service of centralized cataloging and the distribution of printed catalog cards. As soon as the catalog department was set up the possibility of furnishing cards to other libraries was investigated. Miss MacDonald and the librarian were in full agreement that such service should be given, but that the elaborate cataloging practices insisted on by the Library of Congress as essential to the usual cooperative cataloging procedures were prohibitive in cost if the recataloging of the Army Medical Library was ever to be accomplished. On the other hand, a duplication of the facilities of the card division of the Library of Congress would be extravagant. Conferences were held with the authorities at the Library of Congress to discover how this dilemma could best be met. The Library of Congress agreed that the Army Medical Library could be given full authority and responsibility for the cataloging represented by the cards issued in its name. The catalogers of the Army Medical Library are given full access to the official catalog of the Library of Congress and are responsible for seeing that all names used agree with the Library of Congress authority cards if such names are present in the Library of Congress catalogs. The simple forms of descriptive cataloging which were desired by the Army Medical Library will be followed on its cards. The subject headings of both libraries are given, and the classification of the Army Medical Library is accompanied by that of the Library of Congress when the title is in both libraries. The Library of Congress agreed that it would restrict its activities to the addition of copyright information and its class mark when it owned a copy of the volume. Otherwise, it serves solely as a printing and distributing agency for these cards.

\section{MED Series Begun}

To signalize the adoption of simpler forms of cataloging and the assumption of full responsibility by the Army Medical

(Continued on page 53) 
an excellent way to maintain, by addition of new sheets or editions, map series which may already be on hand. The knowledge acquired of map sources and of the scope of map materials available will be of considerable value in planning and making purchases to cover specific areas.

The development and maintenance of a college map library of modest size cannot be left to incidental purchases based on suggestions by faculty members over a period of time. The previous discussion of map sources which illustrated their documentary and fugitive nature shows that an adequate and balanced working collection can be obtained only if a definite plan as to its nature and scope is formulated and only if that plan is administered by an individual who is interested in and responsible for it. The peculiarities of map publications are such that the adequacy of a given map collection is largely a measure of the ability of the librarian responsible for it. A librarian with considerable geographic training will usually be more successful than one without such a background. Training in geography helps to provide a knowledge of spatial relationships which is necessary to an evaluation of map materials. It develops an appreciation of the distributional patterns of phenomena for which map coverage is desirable and it supplies an introduction to the geographical materials from which map information is obtained.

\section{The Recataloging Program of the Army Medical Library}

\section{(Continued from page 44)}

Library, the former series of SG cards was discontinued, and a new series with numbers preceded by MED was begun. In order that medical libraries which might desire to place a subscription to the whole series could obtain cards for all medical books added to the national libraries, the
Library of Congress asked that its own cataloging of medical titles be included in the same series. The first copy for this new departure in cooperative cataloging was sent to the Library of Congress, Oct. I, 1946. Since then cards of the MED series have appeared in increasing numbers. 